\title{
Reaction method control of impurity scattering in C-doped MgB2: proving the role of defects besides $\mathrm{C}$ substitution level
}

\begin{abstract}
In this study, $\mathrm{Si}$ and $\mathrm{C}$ were incorporated into polycrystalline $\mathrm{MgB} 2$ via in situ reaction of $\mathrm{Mg}$ and $\mathrm{B}$ with either $\mathrm{SiC}$ or with separate $\mathrm{Si}$ and $\mathrm{C}(\mathrm{Si}+\mathrm{C})$. The electrical transport and magnetic properties of the two series of samples were compared. The corrected resistivity at $40 \mathrm{~K}, \rho \mathrm{A}(40 \mathrm{~K})$, is higher for the samples reacted with $\mathrm{SiC}$ regardless of the carbon $(\mathrm{C})$ substitution level, indicating larger intragrain scattering because of the simultaneous reaction between $\mathrm{Mg}$ and $\mathrm{SiC}$ and carbon substitution during the formation of $\mathrm{MgB} 2$. In addition, because of the cleaner reaction route for the samples reacted with $\mathrm{SiC}$, the calculated active area that carries current, $\mathrm{AF}$, is twice that of the $(\mathrm{Si}+\mathrm{C})$ samples. On the other hand, the upper critical field, Hc2, was similar for both sets of samples despite their different $\mathrm{C}$ substitution levels, which proves the importance of defect scattering in addition to $\mathrm{C}$ substitution level. Hence, the form of the precursor reactants is critical for tuning the form of Hc2(T).
\end{abstract}

Keyword: MgB2; Carbon doping; Upper critical fields; Carbon substitution; Control of impurities; Defect scattering. 